\title{
Airway efficiency during the use of SCUBA diving mouthpieces
}

\author{
R S Hobson
}

\begin{abstract}
Objective-To investigate the effect of varying interdental bite platform thickness of the scuba mouthpiece on airway efficiency.

Methods-10 male divers had their mean peak flow measured for free breathing, maximum flow with diving mouthpiece, teeth in occlusion, and for five experimental mouthpieces with different thickness of interdental bite platform (1 mm, 2 $\mathrm{mm}, 3 \mathrm{~mm}, 4 \mathrm{~mm}$, and $5 \mathrm{~mm}$ ).

Results-The connecting airway between the demand valve and mouthpiece was found to be a major limiting factor in airway efficiency. An interdental bite platform of $4 \mathrm{~mm}$ resulted in the greatest air flow with a further increase in thickness resulting in air flow restriction.

Conclusions-The use of an interdental bite platform of $4 \mathrm{~mm}$ placed between the premolar and molar teeth ensures the greatest airway efficiency and also results in a design which provides the least temporomandibular joint discomfort for the diver.
\end{abstract}

(Br f Sports Med 1996;30:145-147)

Key terms: scuba; diving; mouthpieces; teeth

Scuba diving is one of the largest adventure sports, with over 50000 active divers in the United Kingdom. ${ }^{1}$ The majority of research has been aimed at understanding the physiological effects of hyperbaric conditions upon the human body. Recently several papers ${ }^{2-6}$ have described disorders of the temporomandibular joint (TMJ) associated with the use of scuba mouthpieces. temporomandibular joint dysfunction (or myofacial pain dysfunction) is a problem occurring in the TMJ or its associated musculature due to an imbalance of the occlusion of the teeth or overexertion of the joint and muscles, resulting in pain. It has been found by Mack et $a l^{7}$ and Goldstien and Katz ${ }^{8}$ that the use of scuba mouthpieces causes an occlusion imbalance which results in excessive loads within the temporomandibular joint and muscles.

All commercially available scuba mouthpieces (fig 1) are of a similar design. There is a connecting airway between the mouthpiece and the second stage of the demand valve, which also secures the two parts together. A labial flange acts to aid the lip seal and an interdental bite platform is gripped between the divers teeth. Research ${ }^{7}$ has highlighted the relation between the position and thickness of the interdental bite platform in the causation of temporomandibular joint dysfunction. The findings recommended that the bite platform should be positioned further posteriorly in the mouth (between the premolars and canine teeth) and be thinner than those commercially available.

As yet there is no information on the efficiency of the scuba mouthpiece in providing an air supply to the diver. Work by Barton and Harris $^{9}$ in a study on airway efficiency in patients following corrective mandibular surgery found that a minimum opening of $4 \mathrm{~mm}$ was required to ensure a patent airway during the immediate postoperative period when the patient's jaws were wired together for fixation.

This study was therefore undertaken to investigate the effect of the mouthpiece design and in particular the thickness of the interdental bite platform on airway efficiency of the diving mouthpiece.

\section{Methods}

Ten male active scuba divers, between the ages of 22 and 30 years and with normal respiratory function were used in the study. All had a complete dentition with normal (Angles class I) occlusion and normal facial skeletal pattern.

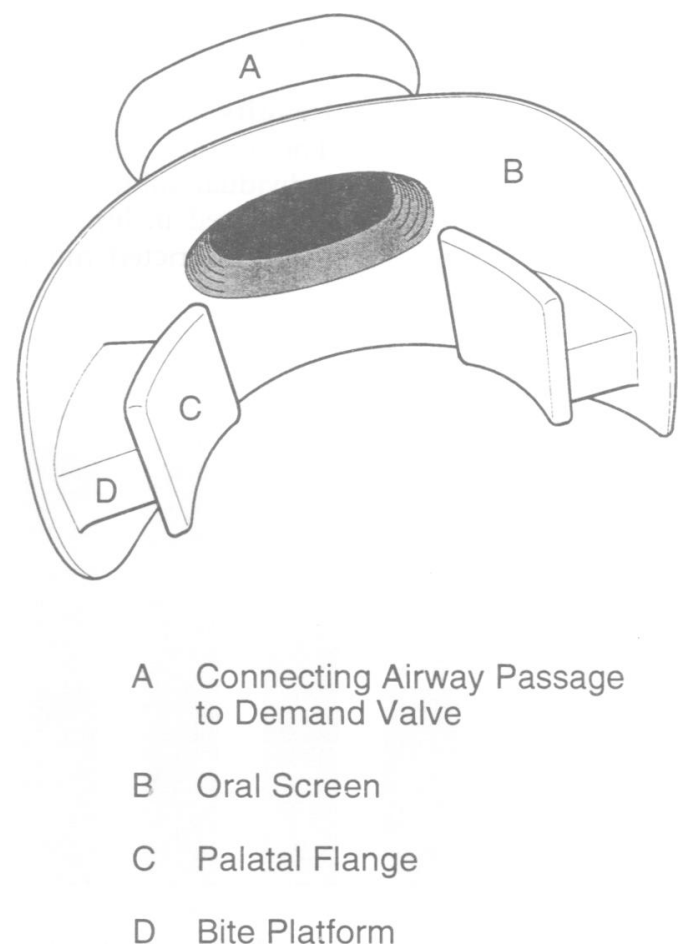

Figure 1 The component parts of the scuba diving mouthpiece. 
Results of peak flow measurement

\begin{tabular}{|c|c|c|c|}
\hline & $\begin{array}{l}\text { Mean peak flow } \\
\left.\text { (litres } \cdot \min ^{-1}\right)(S D)\end{array}$ & $\begin{array}{l}\text { Percentage of } \\
\text { free breathing }\end{array}$ & $\begin{array}{l}\text { Percentage } \\
\text { of } D V_{\max }\end{array}$ \\
\hline Free breathing & $283(15 \cdot 58)$ & 100 & \\
\hline $\begin{array}{l}\mathrm{DV}_{\max } \\
\mathrm{DV}_{\mathrm{occ}}\end{array}$ & $\begin{array}{l}236(14.98) \\
162(17 \cdot 53)\end{array}$ & $\begin{array}{l}83 \cdot 4 \dagger \\
57 \cdot 2 \ddagger\end{array}$ & $\begin{array}{l}100 \\
68 \cdot 6 \ddagger\end{array}$ \\
\hline $\begin{array}{l}\text { DV1 } \\
\text { DV2 } \\
\text { DV3 } \\
\text { DV4 } \\
\text { DV5 }\end{array}$ & $\begin{array}{l}204(15 \cdot 72) \\
211(17 \cdot 51) \\
219(12 \cdot 93) \\
226(16 \cdot 21) \\
216(19 \cdot 63)\end{array}$ & $\begin{array}{l}72 \cdot 1 \\
74 \cdot 6 \\
77 \cdot 3 \\
79 \cdot 8 \\
76 \cdot 3\end{array}$ & $\begin{array}{l}86 \cdot 4^{\star} \\
89 \cdot 4^{\star} \\
92 \cdot 8 \\
95 \cdot 8 \\
91 \cdot 5\end{array}$ \\
\hline
\end{tabular}

Paired Student $t$ test: ${ }^{\star} \mathrm{P}<0.05 \mathrm{P}<0.01 \mathrm{P}<0.001$.

Air flow was measured for five consecutive forced breaths, both inspiration and expiration being recorded using a Morgan spirometer (PK Morgan, Chatham, UK) connected by wide bore tubing to an anaesthetic face mask. The mean peak flow was calculated from the peak flow achieved on each inspiratory and expiratory breath. This represented free breathing (FB).

Following a minimum of 10 minutes rest between recordings, flow rates were measured using a diving mouthpiece consisting of an oral screen only (no bite platform present) with the teeth apart for five consecutive breaths to record maximum flow $\left(\mathrm{DV}_{\max }\right)$. This was repeated with the teeth together in occlusion $\left(\mathrm{DV}_{\text {occ }}\right)$.

The peak flows for a series of experimental mouthpieces were then measured in random order. The design of the mouthpiece was identical to that recommended by Mack et $a l^{7}$ that is, an oral screen constructed of resilient silicone rubber, with interdental bite platforms placed between premolar and molar teeth. The mouthpieces varied in the thickness of the interdental bite platform: $1 \mathrm{~mm}, 2 \mathrm{~mm}, 3 \mathrm{~mm}$, $4 \mathrm{~mm}$, and $5 \mathrm{~mm}$ thick $\left(\mathrm{DV}_{1}\right.$ to $\left.\mathrm{DV}_{5}\right)$. In each case the subject was instructed to grip the mouthpiece as in scuba diving.

The data were analysed using paired Student $t$ tests.

\section{Results}

The results for the peak flow rates for the individual subjects are presented in the table (expressed in litres $\cdot \mathrm{min}^{-1}$ ). It can be seen that the unrestricted mouthpiece $\left(\mathrm{DV}_{\max }\right)$ causes a

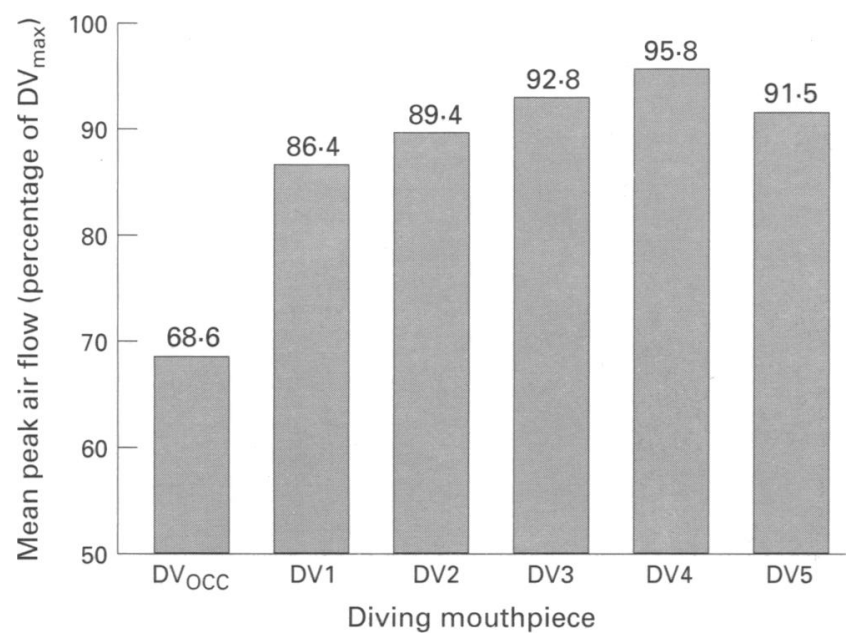

Figure 2 The effect of varying interdental bite platform thickness on mean peak flow rate expressed as a percentage of $D V_{\max }$ significant drop in mean peak flow of 47 litres $\mathrm{min}^{-1}(\mathrm{P}<0.01)$ when compared to free breathing (FB). The mean peak flow rate is further restricted by the teeth in occlusion $\left(\mathrm{DV}_{\text {occ }}\right)$ with a mean restriction of 121 litres $\cdot \min ^{-1}(P<0.001)$ between $F B$ and $D V_{\text {occ }}$.

The effect on peak flow rates with the use of the mouthpieces with different bite interdental bite platform thicknesses compared to DVmax is shown in fig 2. The effect of breathing with the teeth in occlusion $\left(\mathrm{DV}_{\text {occ }}\right)$ causes severe restriction in mean peak air flow. $\mathrm{DV}_{1}$ and $\mathrm{DV}_{2}$ both significantly restrict the peak air flow $(P<0.05)$, with the increase in interdental bite platform thickness to $3 \mathrm{~mm}\left(\mathrm{DV}_{3}\right)$ improving the peak air flow to $92.8 \%$ of $\mathrm{DV}_{\max }$. There is a further improvement in peak air flow to $95.8 \%$ of $\mathrm{DV}_{\max }$ by a thickness of $4 \mathrm{~mm}\left(\mathrm{DV}_{4}\right)$. However, further increase in thickness to $5 \mathrm{~mm}$ $\left(\mathrm{DV}_{5}\right)$ causes a reduction in the airflow to $91.5 \%$ of $\mathrm{DV}_{\max }$

\section{Discussion}

The significant drop in airway efficiency to $83.4 \%$ of free breathing by the use of an unrestricted diving mouthpiece indicates that the design and cross sectional size of the connecting airway between the demand valve second stage and the mouthpiece is a limiting factor in airway efficiency. Modern scuba demand valves are "servo-assisted" by providing air on demand at a pressure slightly higher than the ambient pressure in order to attempt to reduce the physical effort required to breath during diving. This finding of severe airway restriction by the mouthpiece to demand valve connecting airway suggests that an improved design, possibly with an increased cross sectional area of the connection, would reduce the physical effort required to breathe during scuba diving.

The use of a mouthpiece consisting of only an oral screen could have two effects: either to improve the airway efficiency to the maximum possible during exertion, when the teeth are naturally apart, or to severely restrict the airway if the diver maintains his teeth in occlusion. Mack et $a l^{7}$ tested an experimental design of mouthpiece which consisted only of an oral screen, reporting that although the divers found the airway to be efficient, there were major problems with its retention in the mouth during diving, especially upon physical exertion when the teeth are apart. At rest the teeth are naturally apart by approximately 3 $\mathrm{mm}$ (known as the resting freeway space). However, in conditions of stress, as are frequently encountered in diving, the tendency is to clench the teeth tightly together which results in a greatly reduced airway. A design which has no interdental bite platforms is therefore not to be recommended.

The use of a bite platform improves the retention of the mouthpiece during diving. ${ }^{87}$ An interdental bite platform thickness of $4 \mathrm{~mm}$ placed between the premolar and molar teeth is recommended, to provide greatest diver comfort. This study confirms that the bite platform thickness should be between 3-4 mm, to ensure an adequate airway and that the 4 
$\mathrm{mm}$ interdental bite platform provides the most efficient airway.

The effect of further increasing the interdental bite platform thickness to $5 \mathrm{~mm}$ appears to restrict the airway, this may be due to the increased bulk of the interdental bite platforms acting as a physical obstruction to air flow. It is interesting that Barton and Harris ${ }^{9}$ found similar results with wedges thicker than $4 \mathrm{~mm}$ in their study in mandibular osteotomy patients.

\section{CONCLUSIONS}

The limiting factor in scuba mouthpiece air flow is the design of the connecting airway to the mouthpiece. Further work by manufacturers of scuba demand valves should be aimed at improving this design problem.

The use of a mouthpiece consisting only of an oral screen initially appears to have advantages in improving the airway efficiency. However, there are significant problems in the retention of such designs during use. There are further problems that the airway efficiency is severely restricted when the teeth are clenched together. Such a design is not recommended.

The use of an interdental bite platform of 4 $\mathrm{mm}$ placed between the premolar and molar teeth ensures the greatest airway efficiency and also results in a design which provides the least temporomandibular joint discomfort for the diver.

1 British Sub Aqua Club. Annual reports and accounts, 1989

2 Pinto OF. Temporormandibular joint problems in underwater activities. $\mathcal{F}$ Prosthet Dent 1966;16:772-81.

3 Storer R, Bowman A. An unusual factor in disharmony of the masticatory system. Br Dent $\mathcal{f} 1969 ; 126: 80-1$.

4 Roydhouse N. The jaw and scuba diving. $f$ Otolaryngol Soc Aust 1977;4:162-5.

5 Hobson RS. Diving and dental pain. I South Pacific Underwater Med Soc 1987;17:43-6.

6 Hobson RS. Temporomandibular joint dysfunction syndrome associated with scuba diving mouthpieces. $\mathrm{Br}$ Sports Med 1991;25:49-51.

7 Mack P, Hobson RS, Askell J. Dental factors in scuba mouthpiece design. Br Dent f 1985;158:141-2.

8 Goldstien GR, Katz W. Divers mouth syndrome. NY State Dent $\mathcal{F} 1982 ; 10: 523-5$.

9 Barton PR, Harris AN. An investigation into the efficiency of the oral airway and a technique for improving the airway in the early post operative period followin mandibular osteotomy. Br f Oral Surg 1970;19:16-26. 